\title{
Toward a better understanding of strain incompatibilities at grain boundaries in the analysis of fatigue crack initiation at low temperature in the Udimet ${ }^{T M} 720$ Li superalloy
}

\author{
Baptiste Larrouy $^{1,2, a}$, Patrick Villechaise ${ }^{1}$, Jonathan Cormier ${ }^{1}$, and Olivier Berteaux ${ }^{2}$ \\ ${ }^{1}$ Institut Pprime, CNRS - ENSMA - Université de Poitiers, UPR CNRS 3346, Department of Physics and \\ Mechanics of Materials, ENSMA - Téléport 2, 1 avenue Clément Ader, BP. 40109, 86961 Futuroscope \\ Chasseneuil Cedex, France \\ 2 Turbomeca - SAFRAN group, Materials Processes \& Investigations Department, 64511 Bordes Cedex, France
}

\begin{abstract}
Low cycle fatigue properties of polycrystalline $\gamma-\gamma^{\prime}$ Ni-based superalloys are dependent on many factors such as temperature, environment, grain size and distribution of the strengthening phases. Under LCF conditions at intermediate temperatures, an intergranular crack initiation could be observed. In this paper we propose to analyze the local conditions favouring such an intergranular cracking mode considering the high strength $\mathrm{C} \& \mathrm{~W}$ Udimet ${ }^{\mathrm{TM}} 720 \mathrm{Li}$ alloy, widely used for manufacturing high pressure turbine disk for aeroengine applications. Tensile and fatigue tests were performed in air in the $20-465^{\circ} \mathrm{C}$ range of temperature on microsamples in order to focus on plasticity and damage processes developed near grain boundaries. A special attention was paid on the slip transfer between neighbouring grains taking into account their local crystallographic orientations. In some specific crystallographic configurations, small zones were detected at the tip of slip bands presenting an intense elastic/plastic activity. Although they are limited in size, they are associated to local crystalline rotations. High levels of local strain/stress were also evaluated in these volumes using an EBSD pattern cross correlation technique. The development of such specific zones was investigated at different stages of the tensile and LCF behaviour and was identified as leading to micro-cracks initiation for both solicitation modes.
\end{abstract}

\section{Introduction}

Because of their good balance of mechanical properties, microstructure stability and corrosion resistance at high temperatures, as well as their workability, polycrystalline nickel-based superalloys are the most suitable material class to manufacture aeroengines turbine disks [1]. Those components are submitted to a wide range of design criteria such as resistance to disk burst, resistance to creep deformation and dwell-fatigue crack growth for the rim part (exposed to high temperatures up to $\sim 70{ }^{\circ} \mathrm{C}$ ) and finally, a minimum low cycle fatigue (LCF) life for the bore sections (exposed to lower temperatures of up to $550^{\circ} \mathrm{C}$ ) [2]. Low cycle fatigue properties of polycrystalline $\gamma-\gamma^{\prime}$ Ni-based superalloys are dependent on many factors such as temperature, environment, grain size and distribution of the strengthening phases. Under LCF conditions, an intergranular crack initiation is often observed in a large range of temperature [3].

At high temperatures $\left(\mathrm{T}>650^{\circ} \mathrm{C}\right)$, complex interactions between grain boundaries and environment favour the embrittlement of the latter due to oxidation mechanisms, see e.g. [4]. At lower temperature $\left(\mathrm{T}<500^{\circ} \mathrm{C}\right)$, deformation mechanisms close to and through grain boundaries are first order controlling parameters for intergranular crack

\footnotetext{
a Corresponding author: baptiste. larrouy@ensma.fr
}

initiation, especially the interactions between grain/twin boundaries and persistent slip bands [5].

Villechaise \& al. [6] contributed to a better understanding on how plasticity and subsequent damages develop locally at grain boundaries by paying a particular attention to the local crystallographic configuration and its effect on slip transmission from one grain to its neighbour through the grain boundary. They pointed out the contrast in plastic activity between neighbouring grains as a key parameter in the formation at some grain boundaries of micro areas with a different optical contrast than the rest of the grain. These micro-volumes (observed after tensile tests at room temperature), were associated in this study to a localised crystallographic rotation inducing high localised stress/strain fields. The present article is aimed at exploring into deeper details the microstructural factors controlling the nucleation and development of these micro-volumes, as well as their consequences on the fatigue crack initiation.

\section{Experimental}

\subsection{Materials and microstructure characterisations}

The material studied here is the polycristalline Ni-based superalloy Udimet ${ }^{\mathrm{TM}} 720 \mathrm{Li}$ (denoted as $\mathrm{U} 720 \mathrm{Li}$ in the

\footnotetext{
This is an Open Access article distributed under the terms of the Creative Commons Attribution License 4.0, which permits unrestricted use, distribution, and reproduction in any medium, provided the original work is properly cited.
} 
Table 1. U720 Li nominal composition.

\begin{tabular}{|l|c|c|c|c|c|c|c|c|c|c|c|}
\hline Element & $\mathrm{Ni}$ & $\mathrm{Cr}$ & $\mathrm{Co}$ & $\mathrm{Ti}$ & $\mathrm{Mo}$ & $\mathrm{Al}$ & $\mathrm{W}$ & $\mathrm{C}$ & $\mathrm{B}$ & $\mathrm{Zr}$ & $\mathrm{Fe}$ \\
\hline \hline $\mathrm{Wt}(\%)$ & Base & 16.2 & 14.5 & 5 & 2.9 & 2.5 & 1.2 & 0,016 & 0.016 & 0.043 & 0.28 \\
\hline
\end{tabular}

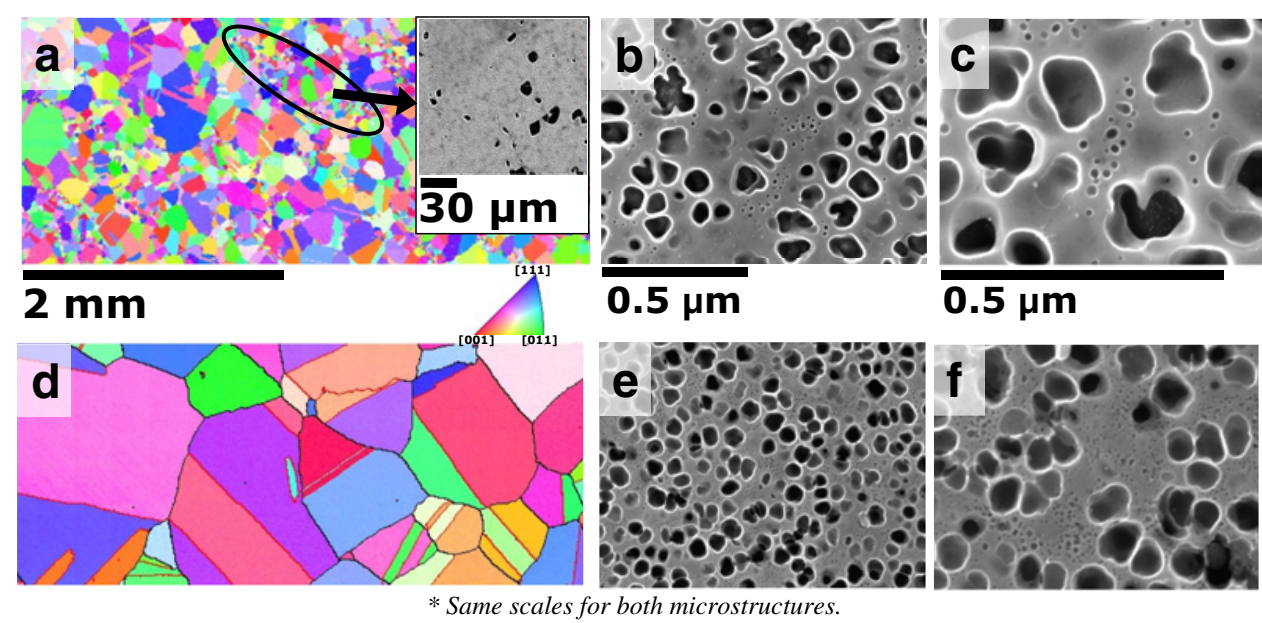

Figure 1. Representative grain structures obtained by EBSD (a, d) and corresponding $\gamma / \gamma^{\prime}$ microstructures (b, c, e, f) for the Duplex (a-c), the Homogeneous (d-f) microstructures. The insert in Fig. 1a is highlighting at some remaining primary $\gamma^{\prime}$ particles in small grain clusters. The $\gamma^{\prime}$ phase appears in dark contrast in (b, c, e and f).

following of this article) whose chemical composition is given in Table 1. Two different microstructures of the U720 Li alloy were studied. These two microstructures are different in terms of grain size, $\gamma^{\prime}$ precipitates size and distribution.

The first one has a bimodal grain size distribution composed of clusters of small grains merged in a coarse grain skeleton (Fig. 1a). This first microstructure is composed of intergranular primary $\gamma^{\prime}$ precipitates in the small grain clusters (insertion in Fig. 1a) and of intragranular secondary and tertiary $\gamma^{\prime}$ precipitates whose respective sizes are typical of supersolvus solution treated U720 Li followed by medium cooling rates $\left(\sim 100^{\circ} \mathrm{C} / \mathrm{min}\right)$ (Fig. 1b \& Fig. 1c). The second microstructure was specially tailored by thermal treatment to study the role of grain boundaries in the development of a localised plasticity; it has a homogeneous coarse grain structure (Fig. 1d) associated to a very fine intragranular $\gamma^{\prime}$ precipitation (secondary + tertiary) (Figs. 1e \& 1f). In the following of the article, those microstructures will be denoted as the "Duplex" and the "Homogeneous" microstructures, respectively. The main microstructural characteristics (average grain size, volume fractions and sizes of primary, secondary and tertiary $\gamma^{\prime}$ particles and average interparticle spacings) determined by image analyses techniques [7], [8] are detailed in Table 2. The average $\gamma$ channels width was taken between the smallest $\gamma^{\prime}$ precipitates. These $\gamma / \gamma^{\prime}$ microstructures (typically shown in Figs. 1b, 1c 1e, 1f) were characterized after chemical etching using a solution made of $33 \% \quad \mathrm{HNO}_{3}$ and $66 \% \mathrm{HCl}$ (vol. parts). By this way, the $\gamma^{\prime}$ phase has been dissolved on the etched surface and appears darker than the $\gamma$ matrix. A field emission gun scanning electron microscope (FEG-SEM) JEOL JSM 7000F was used to observe the samples using a $25 \mathrm{kV}$ acceleration
Table 2. U720 Li Microstructural characteristics of both U720 Li microstructures.

\begin{tabular}{|c|c|c|}
\hline Microstructure & Duplex & Homogenous \\
\hline Av. Grain size $(\mu \mathrm{m})$ & 70 & 350 \\
\hline $\mathrm{V}_{\text {fraction }} \gamma_{1}^{\prime}(\%)$ & 1.2 & - \\
\hline Av. size $\gamma_{\mathrm{n}}^{\prime}(\mathrm{nm})$ & 153 & 81 \\
\hline $\mathrm{V}_{\text {fraction }} \gamma_{\mathrm{n}}^{\prime}(\%)$ & 25.9 & 30.8 \\
\hline Av. size $\gamma_{\mathrm{m}}^{\prime}(\mathrm{nm})$ & 20.7 & 11 \\
\hline $\mathrm{V}_{\text {fraction }} \gamma_{\mathrm{m}}^{\prime}(\%)$ & 0.59 & 2.4 \\
\hline Av. $\mathrm{W}_{\text {channels }}(\mathrm{nm})$ & 110.8 & 31.9 \\
\hline$\Sigma \mathrm{V}_{\text {fraction }} \gamma_{\mathrm{i}}^{\prime}(\%)$ & 27.6 & 33.2 \\
\hline
\end{tabular}

With $V_{\text {fraction }}$ : volume fraction; Av. size: average size; $W_{\text {channels }}$ : interparticle distances, $\gamma_{i}^{\prime}: \gamma^{\prime}$ precipitate population $(I \leq i \leq$ III)). These values are expressed as mean values extracted from a Log-Normal fitting of the sizes distributions.

voltage. It is interesting to note that the Homogeneous microstructure has a slightly higher room temperature $0.2 \%$ yield strength $(978 \mathrm{MPa})$ at $20^{\circ} \mathrm{C}$ compared to the Duplex one (964 MPa).

\subsection{Mechanical testing}

Mechanical tests were performed using flat micro samples whose gauge section is $10 \mathrm{~mm} \times 2 \mathrm{~mm} \times 1 \mathrm{~mm}$, as in previous studies [9]. The samples have been machined out from parallelepipeds $(35 \mathrm{~mm} \times 15 \mathrm{~mm} \times 12 \mathrm{~mm})$ by spark erosion. Before testing, each side of the samples as well as their edges have been mechanically polished until a $1 \mu \mathrm{m}$ diamond spray finish. To achieve a good electron backscattering diffraction (EBSD) quality, the residual stresses and/or deformation caused by mechanical polishing were removed by electrochemical polishing using a solution 
made of 10 pct. (vol. pct) perchloric acid in methanol $\left(4{ }^{\circ} \mathrm{C}, 45 \mathrm{~V}\right)$.

Room temperature tensile tests were performed with a DEBEN micro-machine. Those tensile tests were performed at a very slow strain rate $\left(3 \cdot 10^{-5} \mathrm{~s}^{-1}\right)$ and interrupted at different plastic deformation levels: $\varepsilon_{\mathrm{p}}=0.03 \%, \quad \varepsilon_{\mathrm{p}}=0.15 \%$ and $\varepsilon_{\mathrm{p}}=0.25 \%$ for both microstructures. These plastic strain amplitudes have been selected as representative of fatigue solicitations.

It is here important to note that for both $\mathrm{mi}-$ crostructures, the tensile curve obtained for such micro tensile tests correctly match with the tensile curve obtained on a conventional electromechanical machine with "macroscopic" cylindrical samples, with differences less than $30 \mathrm{MPa}$ for a same total applied strain. The same micro sample geometry was used to perform tensile tests at $465^{\circ} \mathrm{C}$ and cyclic tests (at both $20^{\circ} \mathrm{C}$ and $465^{\circ} \mathrm{C}$ ) using an Instron 1362 electromechanical fatigue machine equipped with a specially designed assembly to test micro samples. Such cyclic tests were only performed on U720 Li samples under load control with an imposed stress level of $880 \mathrm{MPa}$ and stress ratio $\mathrm{R} \sigma=0.05$. They were interrupted at a $0.15 \%$ plastic strain level. The imposed stress was selected in order to reach the plastic strain target after thousands of cycles ( 20000 cycles for the Duplex microstructure and $\sim 5000$ for the Homogeneous one). EBSD characterisations were performed using both JEOL 6100 and JEOL 7000F SEM operating in the $20-25 \mathrm{kV}$ range. A working distance of $15 \mathrm{~mm}$ was chosen. Both characterisations were performed with the OIM software provided by EDAX. EBSD maps were performed with a scan step of 0.2 or $3 \mu \mathrm{m}$.

\subsection{Mechanical testing}

Using the EBSD characterisations, it has then been possible to determine the Schmid factor $\mu$ of the 12 $\{111\}<110>$ octahedral slip systems that can potentially be active in each grain during tensile and fatigue tests using the following relationship:

$\mu=\cos \Phi * \cos \alpha=\left(\frac{\overrightarrow{n_{P G}}}{\left\|\overrightarrow{n_{P G}}\right\|} \cdot \frac{\vec{\sigma}}{\|\vec{\sigma}\|}\right) *\left(\frac{\overrightarrow{D G}}{\overrightarrow{\|D G\|}} \cdot \frac{\vec{\sigma}}{\|\vec{\sigma}\|}\right)$.

The next step consisted in identifying which one(s) of those 12 potential slip systems is/are active from SEM observations after each step of mechanical testing. To do that, the $\Pi$ angle between the stress direction and the visible emergent slip band had to be measured. It was then possible to determine the normal of the active plane according the Eq. (2):

$$
\cos \Pi=\frac{\left(\overrightarrow{n_{P G}} \wedge \overrightarrow{n_{S U R F}}\right) \cdot \vec{\sigma}}{\left\|\overrightarrow{n_{P G}} \wedge \overrightarrow{n_{S U R F}}\right\| *\|\vec{\sigma}\|} .
$$

Such Schmid factor identification(s) for each active slip system have been performed in each grain from the samples gauge length and after each step of the mechanical tests. In this work, the assumption of the highest Schmid factor among the three possible slip systems within the same slip plane was made. The TWIST and TILT angles

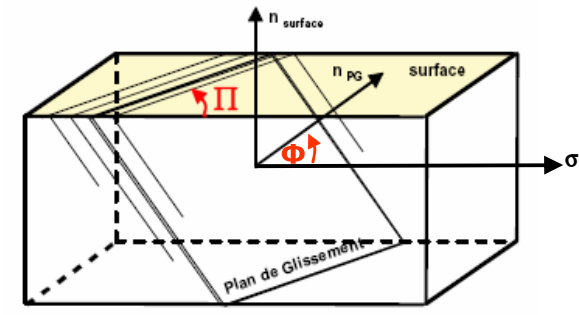

Figure 2. Angles linked to the Schmid factor and TILT/TWIST calculations for the considered activated slip system(s) [9].

between the normals to the activated slip planes on both side of the grain boundary were taken into account in the analysis of the deformation mechanisms (Figs. 5, $6 \&$ 7). The angle $\Phi$ i (Fig. 2) between the normal to one slip plane and the tensile direction in the grain i can be calculated from the formula (1) previously presented:

$$
\Phi_{i}=\cos ^{-1}\left(\frac{\overrightarrow{n_{P G}}}{\left\|\overrightarrow{n_{P G}}\right\|} \cdot \frac{\vec{\sigma}}{\|\vec{\sigma}\|}\right)
$$

Then, the TWIST angle values were obtained by the difference $\Phi 1-\Phi 2$ for activated systems in grains 1 and 2 . The TILT angle value between systems activated in grain 1 and grain 2 can be calculated by using $\pi 1$ and $\pi 2$ from Eq. (2).

\section{Strain localisation at grain boundaries}

On all the U720 Li samples previously described, whatever the deformation mode (monotonic or cyclic), temperature $\left(20^{\circ} \mathrm{C}\right.$ and $\left.465^{\circ} \mathrm{C}\right)$ and the plastic strain $(0.03 \%, 0.15 \%, 0.25 \%)$, slip bands were clearly visible on the surface of the gauge section. For more than $90 \%$ of the crystallographic configurations, the plastic deformation (slip bands) can easily transmit from one grain to its neighbour through the grain boundary. However, as mentioned in the introduction, Villechaise \& al. [6] observed some specific configurations for which the slip transfer at grain boundary does not occur. As a consequence, localised elastic and plastic events close to these special crystallographic configurations and at the tip of active slip bands were observed in the neighbouring grain. These micro areas have a different optical contrast than the rest of the grain using an electron back-scattered imaging mode. These micro-volumes (up to $\sim 30 \mu \mathrm{m}^{3}$ in volume), observed at the tip of some slip bands interacting with grain boundaries, were associated to very intense elastic/plastic strain fields induced by a local crystalline rotation (lattice rotation of up to $\sim 10^{\circ}$ ).

Due to such crystallographic rotation (quantified by EBSD), Villechaise \& al. measured high stress levels (several GigaPascals) locally in these volumes with a recently developed EBSD patterns cross correlation technique [10].

In a similar way, such specific zones were observed at a few grain boundaries in all the previously detailed U720 Li samples of our study, whatever the deformation mode (monotonic, cyclic), temperature $\left(20^{\circ} \mathrm{C}, 465^{\circ} \mathrm{C}\right)$ and the plastic strain $(0.03 \%, 0.15 \%, 0.25 \%)$ are. Some of these configurations are illustrated in Fig. 3. 


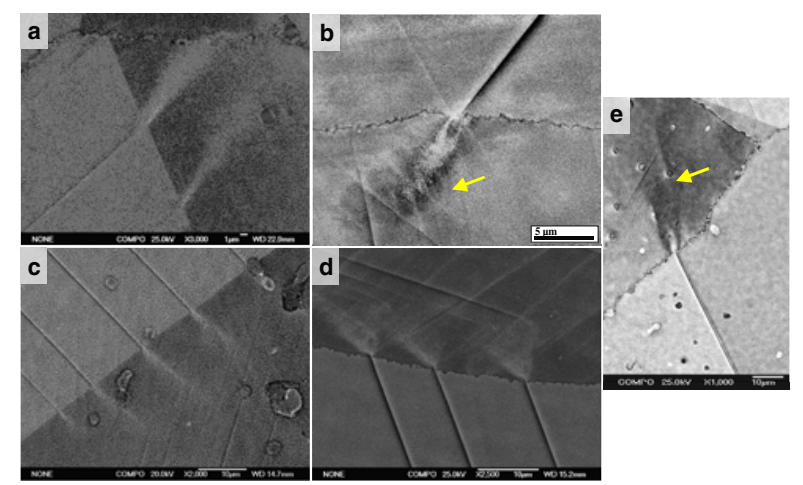

Figure 3. Some illustrations of the occurrence of microvolumes at some grain boundaries: Duplex microstructure/tensile test $/ 20^{\circ} \mathrm{C}(\mathrm{a}, \mathrm{e})$, Homogeneous microstructure/tensile test $/ 20^{\circ} \mathrm{C}$ (b), Duplex microstructure/fatigue test $/ 465^{\circ} \mathrm{C}$ (c) and Homogeneous microstructure/tensile test $/ 465^{\circ} \mathrm{C}$.

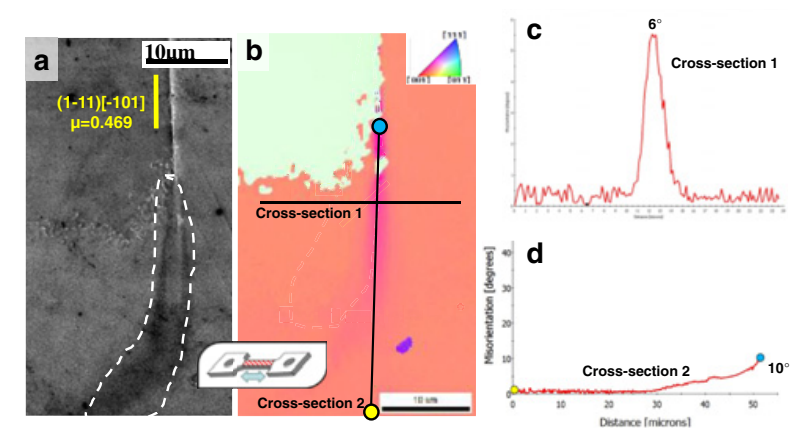

Figure 4. EBSD characterisation of the crystallographic microrotation (b) and misorientation profile (c, d) in a micro-volume (a) - Duplex microstructure/plastic strain $\varepsilon_{\mathrm{p}}: 0.15 \% / 20000$ cycles $/ 20^{\circ} \mathrm{C}$.

In some of these micro-volumes (yellow arrows in Figs. $3 b \& 3 e)$ the activation of a localised slip system contained in it can be noted.

It means that the lattice distortion in these microvolumes has been high enough to trigger a confined plasticity. EBSD characterisations were performed in order to investigate if a crystallographic rotation also occurs at $465^{\circ} \mathrm{C}$ and/or after cyclic deformations.

Figure 4 shows a micro-volume which had developed in the Duplex microstructure after cyclic loading. It is observed a 6 degrees lattice rotation (Fig. 4c) in the crosssection 1 shown in Fig. 4b. This lattice rotation approaches 10 degrees close to the grain boundary (Fig. 4d). Such a crystallographic rotation is observed in the micro-volumes, both under tensile and cyclic loadings.

\section{From strain localisation to crack initiation}

The nocivity of such a strain/stress localisation at grain boundaries has hence been followed during a cyclic test led up to crack initiation. The relatively low level of plastic deformation of the previously presented interrupted tensile $(0.03 \%, 0.15 \%$ and $0.25 \%)$ and fatigue $(0.15 \%)$ tests are indeed not sufficient enough to observe systematically damage traces on the samples. Figure 5 shows two crack initiation configurations after a fatigue test at room temperature for the Duplex microstructure. These surface observations show that cracks initiated either at one side of the analyzed gauge length (crack 1 in Fig. 5a) or in the middle of the gauge length (crack 2 in Fig. 5a). One should notice that these crack initiation sites are not directly linked to a local very large grain configuration. The two cracks clearly initiated from micro-volumes highlighted with white arrows in Fig. 5.

Both cracks initiated at the intersection of a twin boundary with a random grain boundary. In both configurations, gliding occurred on a plane along or slightly shifted from a twin boundary having a very high Schmid factor, close to 0.5 (see Figs. $5 b$ and $5 c$ ). This last point is in good agreement with Miao \& al. work [11] on fatigue crack initiation at $593^{\circ} \mathrm{C}$ of the Nibased superalloy René 88DT. They linked such a cracking mode with the presence of large crystallographic facets on the fracture surface. Such large facets (or chevron shape facets) were also systematically observed on the fracture surface of our U720 Li fatigue samples [12]. Micro-volumes are hence demonstrated to favour crack initiation when they develop at a twin boundary/random grain boundary triple point.

\section{Conditions favouring the development of strain localisation in micro-volumes at a grain boundary ahead of a slip band}

One of the possible conditions leading to the development of the above-mentioned micro-volumes was believed to be the contrast in plastic activity between two neighbouring grains; in other words, the contrast in Schmid factor between the two most favourably activated slip systems on each side of the grain boundary was assumed to favour the development of micro volumes at the interface of these two grains The slip activity occurs first in the grain with the highest Schmid factor and the strain localisation occurs in the "hard" grain side of the grain boundary, with a low Schmid factor [6]. FEG-SEM observations performed on all the samples analyzed in this study brought new insights on the conditions favouring such strain localisation at grain boundaries.

As a first illustration, it is observed in Fig. 6, two neighbouring grains plastically deformed and separated by a grain boundary. Slip traces can be seen in each grain. If an easy slip transmission is observed for the green configuration (see schematic illustration in Fig. 6) a micro volume development is observed just near this easy slip transmission (see red configuration in Fig. 6).

This observation bring a clear evidence that the contrast in Schmid factor across the grain boundary is not a sufficient criteria for the development of a strain localisation due to a difficult slip transmission across the grain boundary.

From FEG-SEM investigations, it was observed that the main criteria leading to the nucleation of these micro-volumes is the TWIST angle between slip planes. Figure 7a shows a favourable geometrical configuration for slip transmission through the grain boundary. In such 


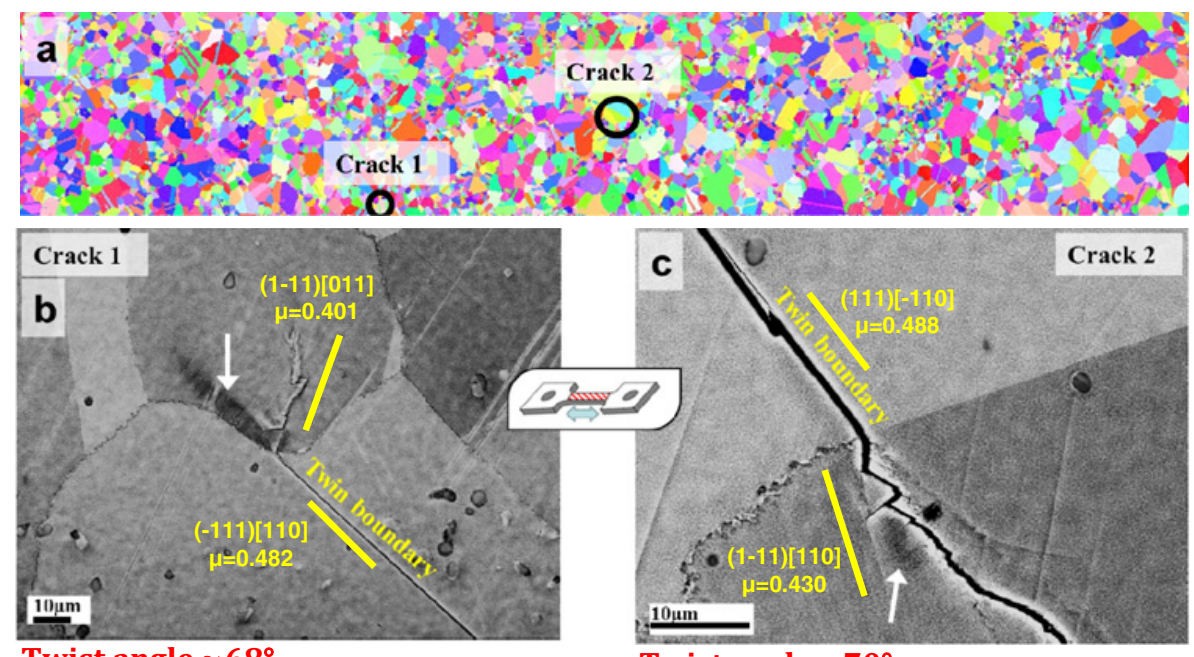

Twist angle $\approx 68^{\circ}$

Twist angle $\approx 70^{\circ}$

Figure 5. Cracks observed after 20000 cycles at $\mathrm{R} \sigma=0.05$ and $\sigma_{\max }=880 \mathrm{MPa}$ on a sample with the Duplex microstructure: crack locations in the sample (a) and corresponding observations under backscattered electron imaging mode. White arrows in (b) and (c) highlight at micro-volumes.

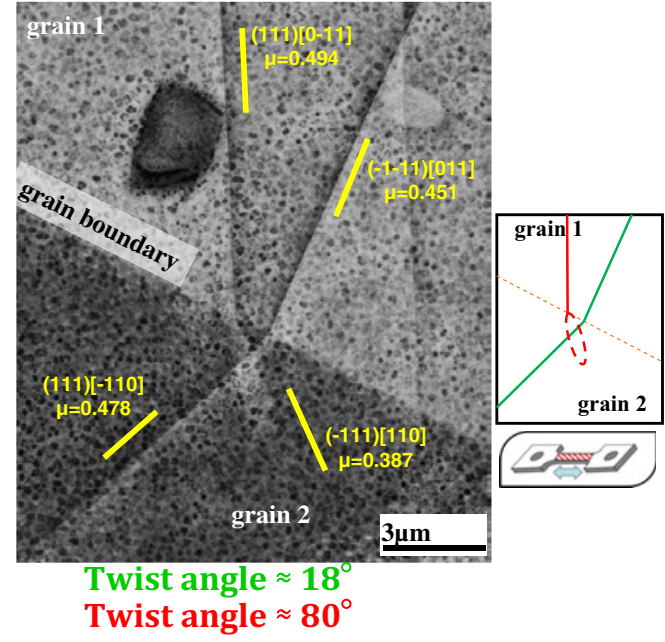

Figure 6. Easy (green) and difficult (red) slip transmission through a grain boundary - After a tensile test up to a plastic strain $\varepsilon_{\mathrm{p}}: 0.25 \%$ for the Duplex microstructure.

a configuration, the normal of the two activated slip planes on both side of the grain boundary are almost coplanar ( $\mathrm{a} \pm 4^{\circ}$ misorientation was measured). Such an easy slip transmission is typically observed for TWIST angles below $\sim 20$ degrees (see e.g. green configuration in Fig. 6) and no strain localisation can be detected, even using a very high magnification.

A difficult slip transmission across the grain boundary is shown in Fig. 7b where the TWIST angle between slip planes is 65 degrees. It is also observed that the crystal lattice is highly twisted at the grain boundary, leading to the first stages of damage nucleation (see yellow arrow in Fig. 7b) which can be consider as the first stage of intergranular cracking. From the present observations, it seems highly probable that the most important parameter controlling the development of strain localisation ahead of a slip band under a hard slip transmission configuration
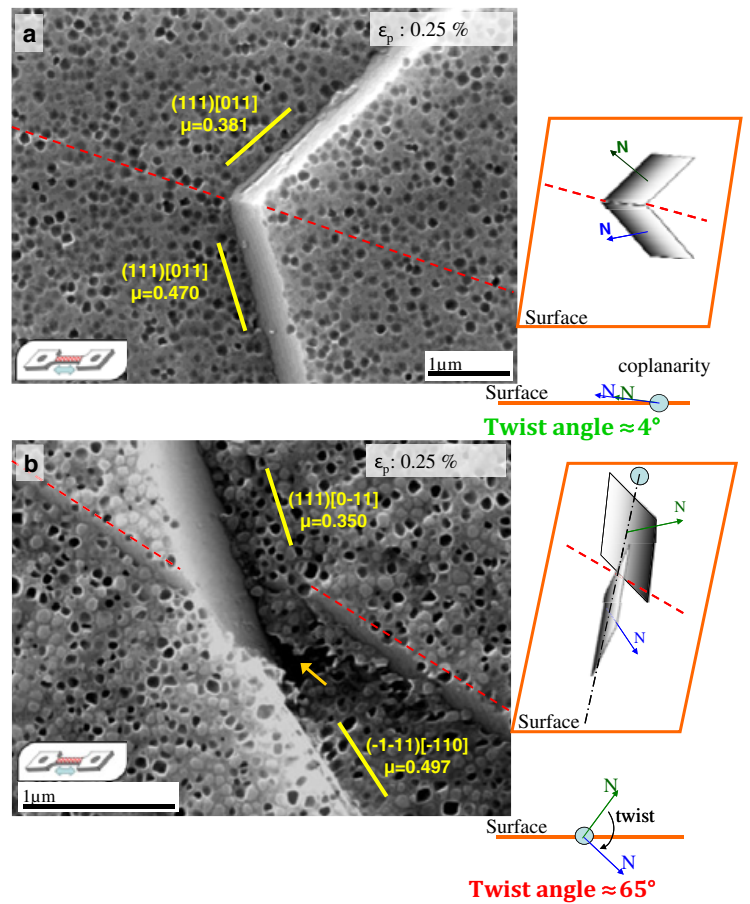

Figure 7. Two geometrical configurations of slip planes on both side of the grain boundary associated to an easy slip transmission (a) and a difficult slip transmission with the development of a micro-volume and of the first stages of micro-cracking (b).

is the TWIST angle magnitude. All the micro-volumes were observed for large TWIST angles (calculations of this TWIST angle have been performed for the slip planes in Figs. 5, $6 \&$ 7, following Eq. (3)). Among all the analyzed configurations, a TWIST angle greater than 55 degrees seems to be necessary for the development of the micro-volumes.

The density of visible micro-volumes on each kind of U720 Li microstructure and each type of loading is analyzed in the Fig. 8. It has been chosen to plot the 


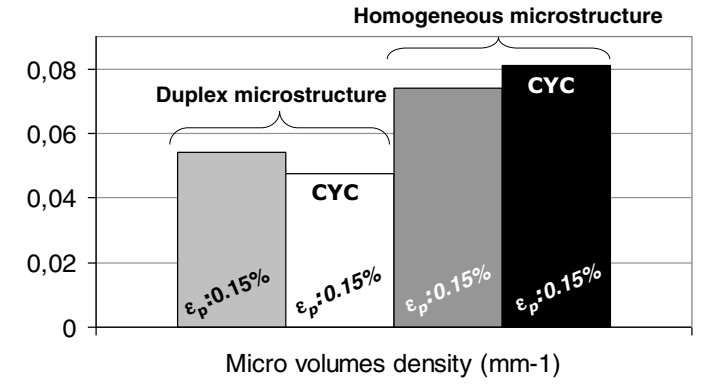

Figure 8. Micro volumes density per grain boundary unit length $\left(\mathrm{mm}^{-1}\right)$ in each sample of $\mathrm{U} 720 \mathrm{Li}$ at $20^{\circ} \mathrm{C}$ for both tensile and cyclic (noted "CYC") loading mode deformed up to $\varepsilon_{\mathrm{p}}=0.15 \%$.

micro-volume linear density based on the grain boundary network length to indirectly take into consideration the difference in grain size between the Homogeneous and Duplex microstructures.

From this figure, the Homogeneous microstructure can be pointed as more "micro-volume sensitive" than the Duplex one, whatever the deformation mode. The main reason for that last point is that the fine and dense $\gamma^{\prime}$ microstructure at grain boundaries of the Homogeneous microstructure is believed to contribute more strongly in the nucleation of the micro volumes by confining the stress/strain field in micro volumes. In contrast, in the case of a coarsened $\gamma^{\prime}$ precipitation with a lower particle density and wider interparticle distances (see Fig. 1 and Table 2), strain/stress incompatibility fields distribute more easily in the whole neighbouring grain, thereby limiting microvolumes development. More results feeding this analysis are available in [12] through a variety of other U720 Li microstructures. More over, such a strain localisation has been highlighted in other Ni-based superalloys [13].

\section{Conclusions}

The following main conclusions can be drawn from the present investigation:

- Whatever the microstructure of the U720 Li alloy, the solicitation mode, the plastic deformation amplitude and the temperature $\left(20^{\circ} \mathrm{C}\right.$ or $\left.465^{\circ} \mathrm{C}\right)$, small areas $\left(\sim 30 \mu \mathrm{m}^{3}\right)$ presenting local crystallographic rotations (up to 10 degrees) have been observed at the tip of slip band interacting with some grain boundaries. Such an elastic deformation induces high stress levels localised in these micro areas. Furthermore, the $\gamma^{\prime}$ precipitation in the neighbourhood of the grain boundary was proved to influence the nucleation and development of these micro-areas.

- Such micro volumes have been proved to be crystallographic sensitive and their nucleation was strongly linked to the local geometrical configuration of the activated slip planes on both side of the grain boundary. These micro-volumes develop under crystallographic configurations where the slip transmission at grain boundary is difficult. Indeed, a high TWIST angle (over $55^{\circ}$ ) between the slip planes from one side to the other of the grain boundary was identified as leading to stress/strain localisation (in the micro volumes).

- These confined volumes were proved to favour fatigue crack initiation at the grain boundary. Microvolumes nucleating from slip along a twin boundary seem even more harmful in terms of crack initiation.

The authors would like to thank Aubert \& Duval for providing the materials and for their continuous interest in this study. Turbomeca-SAFRAN is gratefully acknowledged for its strong collaboration with Institut Pprime on this topic and over a decade on Ni-based superalloys activities.

\section{References}

[1] R.C. Reed, The Superalloys - Fundamentals and Applications, (Cambridge Univ. Press, New York, 2006)

[2] T. Billot, P. Villechaise, M. Jouiad, J. Mendez, Int. J. Fatigue 32 (5), 824-829 (2009)

[3] A. Pineau, S. D. Antolovitch, Chapter 5 In: Joint de Grains et Plasticité Cristalline (Louisette Prester editor: Hermes-Lavoisier, p 225-88), (2011)

[4] E. Chateau, L. Rémy, Mater. Sci. Eng. A 527(7-8), 1655-1664, (2010)

[5] H. Mughrabi, K. Herz, X. Stark, Acta. Metall. 24(7), 659-668, (1976)

[6] P. Villechaise, J. Cormier, T. Billot, J. Mendez, (Ed.TMS, Proceedings of Superalloys 2012, Seven springs, 15-24), (2012)

[7] J-R. Vaunois, J. Cormier, P. Villechaise, A. Devaux, B. Flageolet, (Proceedings of the 7th international conference on Superalloy 718 and derivatives, 199213), (2010)

[8] J. Cormier, X. Milhet, J. Mendez, J. Mater. Sci. 42, 7780-7786, (2007)

[9] F. Bridier, P. Villechaise, J. Mendez, Acta Mater. 53, 555-567 (2005)

[10] A.J. Wilkinson, G. Meaden, D.J. Dingley, Ultramicroscopy 106, 307-313, (2006)

[11] J. Miao, T. M. Pollock, J. W. Jones, Acta Mater. 57, 5964-5974, (2009)

[12] B. Larrouy, (Ph.D. Thesis, Ecole Nationale Supérieure de Mécanique et d'Aérotechnique), (2014)

[13] B. Larrouy, Patrick Villechaise, Jonathan Cormier, Olivier Berteaux, (Proceedings of the 8th international conference on Superalloy 718 and derivatives), (2014) 